\title{
International Business Cycles Redux
}

\author{
Yan Bai and José-Víctor Ríos-Rull
}

University of Rochester, University of Minnesota,

Federal Reserve Bank of Minneapolis,

Mpls Fed, NBER

Wednesday $13^{\text {th }}$ February, 2013 


\section{Punchline}

- Backus-Smith (Backus and Smith (1993)) puzzle: households consume more domestic goods when they are more expensive

- $\operatorname{corr}(R E R, \mathrm{cH} / \mathrm{cF})$ are small and mostly negative in the data.

- Yet standard models (e.g. RBC) predict a perfect correlation.

- Literature: demand shocks, low elasticity between home and foreign goods (Corsetti, Dedola, and Leduc (2008)), non-tradable goods (Engel and Wang (2011)), labor wedge from home production (Karabarbounis (2012)).

- We pose an explanation based on demand shocks in the context of environments where expenditures shape productivity (a la Bai, Ríos-Rull, and Storesletten (2011)). We also obtain

- Countercyclical terms of trade.

- Volatile net exports.

- Lower international cons corr than output's. 


\section{A Lucas-tree model with two Countries and shopping}

- Two countries $j=1,2$

- Each country owns a continuum of trees, measure $T=1$. Each tree yields one fruit per period

- Households in each country derive utilities from goods produced in both countries

- Search friction. If a shopper in country $i$ finds a tree in country $j$, then trade at price $p_{i j}$; otherwise the fruit rots

- Competitive search: agents choose where to search

- A "market" is characterized by a price and a "market tightness"

- $p$ : price

- $Q$ : market tightness 


\section{Matching Technology}

- Output equal the measure of matches:

$$
Y=D^{\alpha} T^{1-\alpha}
$$

- $D$ is the measure of shoppers. $\alpha$ is a parameter.

- Probability that a tree is randomly matched with a shopper (i.e., number of matches per tree):

$$
\Psi_{T}(Q) \equiv \frac{D^{\alpha} T^{1-\alpha}}{T}=\left(\frac{D}{T}\right)^{\alpha}=Q^{-\alpha}=\frac{Y}{T}=Y=C=D^{\alpha},
$$

- Output and productivity depend only on how many shoppers. 


\section{Household problem}

$$
\begin{aligned}
v^{j}(S, b)= & \max _{d^{*}, c^{* *}, b^{\prime}} u\left[H^{c}\left(c^{j j}, c^{j j^{*}}\right), H^{d}\left(d^{j j}, d^{j j^{*}}\right), \theta\right]+\beta E\left\{v^{j}\left(S^{\prime}, b^{\prime}\right) \mid \theta\right\} \\
& \sum_{\ell=j}^{j^{*}} p^{j \ell}(S) c^{j \ell}+b^{\prime}=[1+R(S)] b \\
& c^{i j}=d^{i j} \quad \Psi_{d}\left(Q^{i j}\right) z^{j} \\
& c^{i j^{*}}=d^{j j^{*}} \Psi_{d}\left(Q^{i j^{*}}\right) z^{j^{*}} \\
& S^{\prime}=G(S)
\end{aligned}
$$

FOC:

$$
\begin{aligned}
& u_{c}^{j} H_{j j}^{c}+u_{d}^{j} H_{j j}^{d} /\left(z^{j} \Psi_{d}\left(Q^{i j}\right)\right)=\beta E\left\{\frac{p^{j j}\left(1+R\left(S^{\prime}\right)\right)}{p^{j \prime}}\left(u_{c}^{j \prime} H_{j j}^{c \prime}+u_{d}^{j \prime} H_{j j}^{d \prime} /\left(z^{j^{\prime}} \Psi_{d}\left(Q^{i j \prime}\right)\right)\right)\right\} \\
& {\left[u_{c}^{j} H_{j j}^{c}+u_{d}^{j} H_{j j}^{d} /\left(z^{j} \Psi_{d}\left(Q^{i j}\right)\right)\right] / p^{j j}=\left[u_{c}^{j} H_{j j^{*}}^{c}+u_{d}^{j} H_{j j^{*}}^{d} /\left(z^{j^{*}} \Psi_{d}\left(Q^{i j^{*}}\right)\right)\right] / p^{j j^{*}}}
\end{aligned}
$$

Define the marginal utility of savings $M(S)$ as

$$
M(S)=\beta E\left\{\frac{\left(1+R\left(S^{\prime}\right)\right)}{p^{j \prime} \prime}\left[u_{c}^{j \prime} H_{j j}^{c \prime}+\frac{u_{d}^{j^{\prime}} H_{j j}^{d^{\prime}}}{Z^{j^{\prime}} \Psi_{d}\left(Q^{j j^{\prime}}\right)}\right] \mid \theta\right\} .
$$




\section{Competitive search}

The reward for a household to send a shopper to market $j \ell$ is

$$
\max _{\{p, Q\}} u_{d}^{j}(S) H_{j \ell}^{d}(S)+z^{\ell} \Psi_{d}(Q)\left[u_{c}^{j}(S) H_{j \ell}^{c}(S)-p M(S)\right]
$$

subject to

$$
\zeta^{\ell} \leq p \Psi_{T}(Q) z^{\ell}
$$

FOC

$$
(1-\alpha) z^{\ell} A Q^{-\alpha} u_{c}^{j}(S) H_{j \ell}^{c}(S)-\varsigma^{\ell} M(S)=0 .
$$

Thus

$$
p=(1-\alpha) \frac{u_{c}^{j}(S) H_{j \ell}^{c}(S)}{M(S)}
$$




\section{Equilibrium}

A competitive equilibrium is a set of decision rules, $C^{j \ell}(S, b)$, $D^{j \ell}(S, b)$, and $b_{j}^{\prime}(S, b)$, share of tress $T^{j \ell}(S)$, and prices $p^{j \ell}(S)$, $R(S)$, the rate of return on trees $\zeta^{\ell}(S)$ so that

1. The decision rules $c^{j \ell}(S, b), d^{j \ell}(S, b)$, and $b_{j}^{\prime}(S, b)$ solve each country's problem (1).

2. Shoppers and trees search optimally in the market for goods, i.e. $\left(p^{j \ell}(S), Q^{j \ell}(S), \zeta^{\ell}(S)\right)$ satisfy the search conditions (6) and (7), where market tightness is $Q^{j \ell}=T^{j \ell} / D^{j \ell}$.

3. Market clearing conditions

$$
\begin{gathered}
C^{j \ell}(S, b)=A\left(D^{j \ell}\right)^{\alpha}\left(T^{j \ell}\right)^{1-\alpha} z^{\ell} \\
b_{j}^{\prime}\left(S, b_{j}\right)+b_{j^{*}}^{\prime}\left(S, b_{j^{*}}\right)=2
\end{gathered}
$$




\section{Example}

Suppose

- Two countries are symmetric

- Utility

$$
u\left(H^{c}, H^{d}\right)=\theta \log \left(H^{c}\right)-H^{d}
$$

- Aggregators

$$
\begin{gathered}
H^{c}\left(c^{j j}, c^{j j^{*}}\right)=\left(c^{j j}\right)^{\mu}\left(c^{j j^{*}}\right)^{1-\mu} \\
H^{d}\left(d^{j j}, d^{j j^{*}}\right)=d^{j j}+d^{j j^{*}}
\end{gathered}
$$

- Complete markets 


\section{Real exchange rate, consumption, and TFP}

- TFP

$$
\widehat{T F P_{1}}=\hat{z}_{1}+\alpha\left[\mu \hat{\theta}_{1}+(1-\mu) \hat{\theta}_{2}\right]
$$

- Relative consumption

$$
\hat{c}_{1}-\hat{c}_{2}=\left[1-(2 \mu-1)^{2}(1-\alpha)\right]\left(\hat{\theta}_{1}-\hat{\theta}_{2}\right)+(2 \mu-1)\left(\hat{z}_{1}-\hat{z}_{2}\right)
$$

- Real exchange rate (RER)

$$
\widehat{R E R}=\left(\hat{\theta}_{2}-\hat{\theta}_{1}\right)+\left(\hat{c}_{1}-\hat{c}_{2}\right)
$$




\section{Real exchange rate, consumption, and TFP}

- Under demand shocks

$$
\begin{aligned}
\widehat{R E R} & =-\left[\frac{(2 \mu-1)^{2}(1-\alpha)}{1-(2 \mu-1)^{2}(1-\alpha)}\right]\left(\hat{c}_{1}-\hat{c}_{2}\right) \\
\widehat{T F P_{1}}-\widehat{T F P_{2}} & =\frac{\alpha(2 \mu-1)}{1-(2 \mu-1)^{2}(1-\alpha)}\left(\hat{c}_{1}-\hat{c}_{2}\right)
\end{aligned}
$$

- Under productivity shocks

$$
\begin{aligned}
\widehat{R E R} & =\left(\hat{c}_{1}-\hat{c}_{2}\right) \\
\widehat{T F P_{1}}-\widehat{T F P_{2}} & =\frac{1}{2 \mu-1}\left(\hat{c}_{1}-\hat{c}_{2}\right)
\end{aligned}
$$

- Standard IRBC model corresponds to $\alpha=0$. With only one shock, it fails to account for positively correlated consumption and TFP or negatively correlated RER and relative consumption.

- Our shopping model can generate both with only demand shock 


\section{The two country two good model with shopping}

- Two countries $j=\{1,2\}$ with representative agents in each.

- Build a top of stochastic growth model.

- There are incomplete markets (no insurance for preference shocks).

- There is perfect mobility of capital without impediments to cross country ownership. 


\section{Preferences: Current utility of Households in country $j$}

$$
u\left[H^{c}\left(c^{j j}, c^{j j^{*}}\right), n^{j}, H^{d}\left(d^{j j}, d^{j j^{*}}\right), \theta^{j}\right]
$$

- $H^{c}\left(c^{j j}, c^{j j^{*}}\right)$ is an (Armington) aggregator of the home $\left(c^{j j}\right)$ and the foreign $\left(c^{j j^{*}}\right)$ good.

- $n^{j}$ are hours worked in country $j$.

- $H^{d}\left(d^{j j}, d^{j j^{*}}\right)$ is an aggregator (maybe linear) of search shopping effort at home $\left(d^{j j}\right)$ and abroad $\left(d^{j j^{*}}\right)$.

- $\theta^{j}$ is a Markovian preference shock.

- Households cannot change their country of residence, which makes labor immobile. Like in Bai, Ríos-Rull, and Storesletten (2011) consumption requires that the household finds the goods which in turn requires enough shopping effort to find them. 


\section{Production in each country}

- Measure one of firms-locations with installed capital $k^{j}$ (depreciates at rate $\delta$ ). Goods can be used for consumption or investment and capacity is

$$
F\left(k^{j}, n^{y j}\right)=\bar{z} \quad\left(k^{j}\right)^{\gamma_{k}}\left(n^{y j}\right)^{\gamma_{n}}
$$

- New capital consists of an (Armington) aggregator of home and foreign investment goods:

$$
k^{\prime j}=(1-\delta) k^{j}+H^{i}\left(i j j, i j j^{*}\right)
$$

- New capital has to be purchased that requires shoppers looking for the home investment good $n^{k j j}$ and for the foreign investment $\operatorname{good} n^{k j j^{*}}$.

- Output in each country can be used by home consumers, foreign consumers, home investors and foreign investors.

- Unmatched capacity rots. 


\section{Households}

Preferences are

$$
u\left[H^{c}\left(c^{j j}, c^{j j^{*}}\right), n^{j}, H^{d}\left(d^{j j}, d^{j j^{*}}\right), \theta^{j}\right]
$$

Again both consumptions require that they are shopped so

$$
\begin{aligned}
c^{j j} & =d^{j j} \Psi_{d}\left(Q^{c j j}\right) F^{c j j} \\
c^{j j^{*}} & =d^{j j^{*}} \Psi_{d}\left(Q^{c j j^{*}}\right) F^{c j j^{*}}
\end{aligned}
$$

- $\Psi_{d}\left(Q^{c j \ell}\right)$ is the probability that a country $j$ consumption shopper has of matching a consumption firm from country $\ell$ that catters to $j$ shoppers. $Q^{c j \ell}$ is market tightness in that consumption goods market and $F^{c j l}$ is its output capacity.

- Households own shares of a mutual fund that owns all firms. 


\section{A few lemmas alleviate notation}

1. The state of the economy is $S=\left\{\theta^{1}, \theta^{2}, K^{1}, K^{2}, B^{1}\right\}$ where $K^{j}$ is capital installed in country $j$ and $B^{1}$ is the share of total wealth held by country 1 households.

2. There are two active markets in consumption goods (one for locals and the other for foreigners) and two markets in investment goods in each country for a total of 8 markets.

3. Firms that produce consumption and investment, for local buyers and to export choose the same inputs $F^{c j j}=F^{i \ell j}=. .=F\left(K^{j}, N^{y j}\right)=F^{j}(S)$. We use $n(k, F)$ to denote the inverse $f(k, n)$.

4. All firms in each country get the same expected revenue (but not necessarily the same price and market tightness). 


\section{The household problem}

$$
\begin{gathered}
v^{j}(S, b)=\max _{c \cdot, d^{\cdot \cdots, n, b^{\prime}}} u\left[H^{c}\left(c^{j j}, c^{j j^{*}}\right), n^{j}, H^{d}\left(d^{j j}, d^{j j^{*}}\right), \theta^{j}\right]+\beta E\left\{v^{j}\left(S^{\prime}, b^{\prime}\right)\right. \\
b^{\prime}+\sum_{\ell=j}^{j^{*}} p^{c j \ell}(S) c^{j \ell}=b[1+R(S)]+n^{j} w^{j}(S) \\
c^{j \ell}=d^{j \ell} \Psi_{d}\left(Q^{c j \ell}(S)\right) F^{c j \ell}(S) \quad \ell=j, j^{*} \\
S^{\prime}=G(S)
\end{gathered}
$$




\section{The household problem - First Order Conditions}

Hholds' FOC (and RA): for $\ell=j, j^{*}$ and $m=j, j^{*}$

$$
\begin{aligned}
u_{c}^{j} H_{\ell}^{c j}-\frac{u_{d}^{j} H_{\ell}^{d j}}{\Psi_{d}^{c j \ell} F^{c j \ell}} & =\beta E\left\{\frac{p^{c j \ell}\left(1+R^{\prime}\right)}{p^{c j m \prime}}\left[u_{c}^{j \prime} H_{m}^{c j \prime}-\frac{u_{d}^{j \prime} H_{m}^{d j \prime}}{\Psi_{d}^{c j m \prime} F^{c k m \prime}}\right] \mid \theta\right\} \\
u_{c}^{j} H_{\ell}^{c}-\frac{u_{d}^{j} H_{\ell}^{d}}{\Psi_{d}^{c j \ell} F^{c j \ell}} & =u_{n} \frac{p^{c j \ell}}{w^{j}} \\
\frac{1}{p^{c j \ell}}\left[u_{c}^{j} H_{\ell}^{c j}-\frac{u_{d}^{j} H_{\ell}^{d j}}{\Psi_{d}^{c j \ell} F^{c j \ell}}\right] & =\frac{1}{p^{c j m}}\left[u_{c}^{j} H_{m}^{c j}-\frac{u_{d}^{j} H_{m}^{d j}}{\Psi_{d}^{c j m} F^{c j m}}\right]
\end{aligned}
$$

Define marginal utility of savings $M(S)$ :

$$
M(S)=\beta E\left\{\frac{\left(1+R^{\prime}\right)}{p^{c j m \prime}}\left[u_{c}^{j \prime} H_{m}^{c j \prime}-\frac{u_{d}^{j \prime} H_{m}^{d j \prime}}{\Psi_{d}^{c j m \prime} F^{c k m \prime}}\right] \mid \theta\right\}
$$




\section{Consumption (or invt) firms in a $(p, F, Q)$ submarket}

- It does not matter whether it sells it home or abroad, $C$ or $I$.

$$
\begin{aligned}
\widehat{\Omega}^{j}(S, k, p, F, Q)= & \max _{n^{k .,}, k^{\prime}, i j, i j j^{*}} \Psi_{T}(Q) p F-w^{j}(S)\left[n(k, F)+n^{k j j}+n^{k j j^{*}}\right] \\
& \quad-p^{i j j}(S) i^{j j}-p^{i j j^{*}}(S) i^{j j^{*}}+E\left\{\frac{\Omega^{j}\left(S^{\prime}, k^{\prime}\right)}{1+R\left(S^{\prime}\right)} \mid \theta\right\} \\
\text { s.t. } \quad i^{j \ell}=\left(n^{k j \ell} \zeta\right) \Psi_{d}\left[Q^{i j \ell}(S)\right] F^{\ell}(S), \quad \text { for } \ell=j, j^{*} & \\
k^{\prime} & =(1-\delta) k+H^{i}\left(j j, j i j^{*}\right), \\
& S^{\prime}=G(S) .
\end{aligned}
$$

with FOC (and RA condition) for $\ell=j, j^{*}$

$$
H_{\ell}^{i j} E\left\{\frac{\Omega_{k}^{j}\left(S^{\prime}, K^{j \prime}\right)}{1+R\left(S^{\prime}\right)} \mid \theta\right\}=\frac{w^{j}(S)}{\zeta \Psi_{d}\left[Q^{i j \ell}(S)\right] F^{\ell}(S)}+p^{i j \ell}(S) .
$$




\section{Equilibrium Properties}

- Markets are now indexed by good type (country of production), quantity, price, and market tightness.

- There are four possible purchasers of goods (home and foreign, consumption and investment. A total of 8 markets.

- We get additional conditions from the FOC of shoppers given expected revenue for sellers.

- The equilibrium objects (44) are functions of $(S)$ for

$\left\{Q^{c j \ell}, Q^{i j \ell}, N^{k j \ell}, C^{j \ell}, I^{j \ell}, p^{c j \ell}, p^{i j \ell}, T^{c j \ell}, T^{i j \ell}, w^{j}, N^{y j}, N^{j}, B^{\prime}, R\right\}_{j \in\{1,2\}, \ell \in\{1,2\}}$. 


\section{Competitive Search in Consumption Market $c^{j \ell}$}

- The rewards for the hhold to send a shopper to a $(p, F, Q)$ market are

$$
\begin{gathered}
\Phi=\max _{Q, p, F}-u_{d}^{j}(S) H_{\ell}^{d j}(S)+\Psi_{d}(Q) F\left(u_{c}^{j}(S) H_{\ell}^{c j}(S)-p M(S)\right) \\
\varsigma \leq p \frac{\Psi_{d}(Q)}{Q} F-w^{\ell}(S) n(k, F) .
\end{gathered}
$$

Solving $p$ from equation (8) and plugging it into the objective function, we have (and ignoring the sunk shopping cost)

$$
\max _{Q, F} \Psi_{d}(Q) F\left(u_{c}^{j}(S) H_{\ell}^{c j}(S)-\frac{\varsigma+w^{\ell}(S) n(k, F)}{\Psi_{d}(Q) F / Q} M(S)\right) .
$$




\section{Competitive Search in Consumption Market $c^{j \ell}$}

First order condition over $Q$ :

$$
(1-\alpha) A(Q)^{-\alpha} F u_{c}^{j}(S) H_{\ell}^{c j}(S)-\left[\varsigma+w^{\ell}(S) n(k, F)\right] M(S)=0 .
$$

First order condition over $F$ :

$$
A(Q)^{1-\alpha} u_{c}^{j}(S) H_{\ell}^{c j}(S)-w^{\ell}(S) \frac{d n(k, F)}{d F} Q M(S)=0
$$

Thus, two equations characterize the equilibrium in market $c^{j \ell}$,

$$
\begin{aligned}
p^{c j \ell} & =(1-\alpha) \frac{u_{c}^{j}(S) H_{\ell}^{c j}(S)}{M(S)}, \\
\frac{w^{\ell}(S)}{p^{c j \ell}} & =\frac{1}{1-\alpha} \frac{\Psi_{d}\left(Q^{c j \ell}\right)}{Q^{c j \ell}} f_{n}(S) .
\end{aligned}
$$




\section{Competitive Search in Investment Market $j \ell$}

The rewards for a firm to send a shopper to a $(p, F, Q)$ market is

$$
\begin{gathered}
\Phi_{F}=\max _{Q, p, F}-w^{j}(S)+\zeta \Psi_{d}(Q) F\left[H_{\ell}^{i j}(S) E\left\{\Omega\left(S^{\prime}, k^{\prime}\right) \Pi\left(S, S^{\prime}\right)\right\}-p\right] \\
\varsigma \leq p \frac{\Psi_{d}(Q)}{Q} F-w^{\ell}(S) n(k, F)
\end{gathered}
$$

Solving $p$ from equation (9) and plugging it into the objective function, we have (and ignore the sunk wage cost)

$$
\max _{Q, p, F} \zeta \Psi_{d}(Q) F\left[H_{\ell}^{i j}(S) E\left\{\Omega\left(S^{\prime}, k^{\prime}\right) \Pi\left(S, S^{\prime}\right)\right\}-\frac{\zeta+w^{\ell}(S) n(k, F)}{\Psi_{d}(Q) F / Q}\right]
$$




\section{Competitive Search in Investment Market ijl}

First order condition over $Q$ :

$$
(1-\alpha) A Q^{-\alpha} F H_{\ell}^{i j}(S) E\left\{\Omega\left(S^{\prime}, k^{\prime}\right) \Pi\left(S, S^{\prime}\right)\right\}-\left[\varsigma+w^{\ell}(S) n(k, F)\right]=0
$$

First order condition over $F$ :

$$
A Q^{1-\alpha} H_{\ell}^{i j}(S) E\left\{\Omega\left(S^{\prime}, k^{\prime}\right) \Pi\left(S, S^{\prime}\right)\right\}-w^{\ell}(S) \frac{d n(k, F)}{d F} Q=0
$$

Thus, two equations characterize the equilibrium in market ij $\ell$,

$$
\begin{aligned}
p & =(1-\alpha) H_{\ell}^{i j}(S) E\left\{\Omega\left(S^{\prime}, k^{\prime}\right) \Pi\left(S, S^{\prime}\right)\right\} \\
\frac{w^{\ell}(S)}{p} & =\frac{1}{1-\alpha} \frac{\Psi_{d}(Q)}{Q} f_{n}(S)
\end{aligned}
$$


Lemma: All firms with $k=K^{j}$ in country $j$ choose the same labor

The revenue of a firm in country $j$ to produce $m$ goods $(x=c, i)$ for country $\ell=j, j^{*}$ is given by

$$
\begin{aligned}
\varsigma^{\chi \ell j} & =p^{\times \ell j} A\left[Q^{\chi \ell j}(S)\right]^{-\alpha} F^{\chi \ell j}-w^{j}(S) n\left(K^{j}, F^{x \ell j}\right) \\
& =w^{j}(S)\left[\frac{p^{\chi \ell j} A\left[Q^{x \ell j}(S)\right]^{-\alpha}}{w^{j}(S)} F^{x \ell j}-n\left(K^{j}, F^{\times \ell j}\right)\right]
\end{aligned}
$$

Using the equilibrium condition from competitive search, $\frac{w^{j}(S)}{p^{\chi \ell j}}=\frac{1}{1-\alpha} A\left[Q^{\times \ell j}(S)\right]^{-\alpha} f_{n}(S)$, we can rewrite firm's revenue

$$
\varsigma^{\times \ell j}=w^{j}(S)\left[(1-\alpha) \frac{F^{\times \ell j}}{f_{n}\left(K^{j}, n\left(K^{j}, F^{\times \ell j}\right)\right)}-n\left(K^{j}, F^{\times \ell j}\right)\right] .
$$

In equilibrium, all firms in country $j$ have the same revenue, $\varsigma^{c j j}=\varsigma^{c j^{*} j}=\varsigma^{i j j}=\varsigma^{i j^{*} j}$, and thus have the same output and the same labor. 


\section{Recursive Equilibrium}

1. Households and firms solve their problems (12 in households, 4 in firms).

2. Competitive Search Conditions. (16).

3. Representative Agent Conditions

4. Market Clearing Conditions for $j$ : (12)

$$
\begin{aligned}
N^{j} & =N^{y j}+N^{k j j}+N^{k j j^{*}}, \\
X^{j \ell} & =T^{x j \ell} \Psi_{T}\left(Q^{x j \ell}\right) F\left(K^{\ell}, N^{y \ell}\right) \quad \text { for } X=\{C, I\}, \ell=\left\{j, j^{*}\right\} \\
1 & =\sum_{\ell=j}^{j^{*}}\left(T^{c j \ell}+T^{i j \ell}\right) \quad \text { for } j \in\{1,2\}
\end{aligned}
$$

5. Value of all firms is 1. 


\section{Putting the model to work}

- We want a clear version of this model. So separable utility with constant Frisch elasticiy and Cobb-Douglas technology. We will place shocks on preferences and on the investment shopping technology.

- Preferences

$$
u\left(H^{c}, n, d^{j}, d^{j^{*}}, \theta\right)=\theta \frac{\left(H^{c}\right)^{1-\sigma}}{1-\sigma}-\chi \frac{\left(n^{j}\right)^{1+\psi}}{1+\psi}-\left(d^{j}+d^{j^{*}}\right)
$$

- Aggregator

$$
H^{c}\left(c^{j}, c^{j^{*}}\right)=\left[\mu\left(c^{j}\right)^{\eta}+(1-\mu)\left(c^{j^{*}}\right)^{\eta}\right]^{\frac{1}{\eta}}
$$

- Production function

$$
F\left(k, n^{y}\right)=\bar{z} k^{\gamma_{k}}\left(n^{y}\right)^{\gamma_{n}}
$$

- Shocks

$$
\log \left(\theta_{t}\right)=\rho_{\theta} \log \left(\theta_{t-1}\right)+v_{t}, \quad v_{t} \sim N\left(0, \Sigma^{2}\right)
$$




\section{Calibration}

\begin{tabular}{|c|c|c|c|}
\hline Targets & Value & Parameter & Value \\
\hline \multicolumn{4}{|c|}{ First Group: Parameters Set Exogenously } \\
\hline Risk aversion & 2. & $\sigma$ & 2. \\
\hline Real interest rate & $4 \%$ & $\beta$ & 0.99 \\
\hline Frisch elasticity & 0.72 & $\frac{1}{\nu}$ & 0.72 \\
\hline \multirow[t]{2}{*}{ Armington elasticity } & 1.1 & $\nu^{\nu}$ & 0.09 \\
\hline & & $\alpha$ & 0.25 \\
\hline \multicolumn{4}{|c|}{ Second Group: Standard Targets } \\
\hline Fraction of time spent working & $30 \%$ & $\chi$ & 2.38 \\
\hline Physical capital to output ratio & 2.75 & $\hat{\delta}$ & 0.07 \\
\hline Consumption share of output & 0.80 & $\gamma_{k}$ & 0.31 \\
\hline Labor share of income & 0.67 & $\gamma_{n}$ & 0.45 \\
\hline Steady-state output & 1 & $\bar{z}$ & 1.10 \\
\hline Import share & 0.10 & $\mu$ & 0.88 \\
\hline \multicolumn{4}{|c|}{ Third Group: Targets Specific to This Economy } \\
\hline Capacity utilization of consumption sector & 0.81 & A & 1.66 \\
\hline Capacity utilization of investment sector & 0.81 & $\zeta$ & 0.38 \\
\hline \multicolumn{4}{|c|}{ Implications over Other Aggregate Variables } \\
\hline Share of production workers & & & 0.90 \\
\hline
\end{tabular}




\section{Results}

\begin{tabular}{|c|c|c|c|c|c|c|c|}
\hline \multirow[t]{2}{*}{ Quantities } & \multirow[t]{2}{*}{ Data } & \multicolumn{2}{|c|}{ IRBC } & \multicolumn{4}{|c|}{ Shopping Model } \\
\hline & & $\mathrm{Y}$ & Z & $Y^{c}$ & $Y^{u c}$ & $Z^{c}$ & $Z^{u c}$ \\
\hline \multicolumn{8}{|l|}{ A. Variance (US) } \\
\hline Output & 1.76 & 1.76 & 0.57 & 1.75 & 1.76 & 2.16 & 2.05 \\
\hline Consumption & 0.98 & 0.06 & 0.02 & 1.52 & 1.77 & 2.48 & 2.06 \\
\hline Investment & 13.74 & 37.43 & 12.43 & 21.88 & 26.02 & 37.32 & 30.25 \\
\hline Employment & 1.16 & 0.14 & 0.05 & 1.44 & 1.52 & 1.97 & 1.76 \\
\hline Net exports & 0.16 & 0.01 & 0.006 & 0.44 & 0.62 & 0.98 & 0.72 \\
\hline TFP & 0.63 & 1.17 & 0.38 & 0.29 & 0.28 & 0.31 & 0.32 \\
\hline Terms of trade & 4.98 & 0.15 & 0.06 & 6.39 & 8.79 & 13.84 & 10.22 \\
\hline \multicolumn{8}{|c|}{ B. International comovement } \\
\hline Output & 0.40 & 0.40 & 0.22 & 0.40 & 0.16 & -0.10 & 0.16 \\
\hline Consumption & 0.25 & 0.38 & 0.20 & 0.15 & -0.11 & -0.35 & -0.11 \\
\hline Investment & 0.23 & 0.26 & 0.08 & -0.65 & -0.80 & -0.89 & -0.80 \\
\hline Employment & 0.21 & 0.45 & 0.28 & 0.15 & -0.12 & -0.37 & -0.12 \\
\hline TFP & 0.30 & 0.39 & 0.21 & 0.73 & 0.57 & 0.36 & 0.57 \\
\hline \multicolumn{8}{|c|}{ C. Co-movement within a country } \\
\hline Net exports, Output & -0.49 & -0.50 & -0.56 & -0.51 & -0.61 & -0.71 & -0.62 \\
\hline Terms of trade, Output & -0.33 & 0.46 & 0.52 & -0.51 & -0.61 & -0.71 & -0.61 \\
\hline $\mathrm{RER}, \mathrm{cH} / \mathrm{cF}$ & -0.71 & 0.99 & 0.99 & -0.96 & -0.96 & -0.96 & -0.96 \\
\hline
\end{tabular}




\section{Sensitivity analysis}

\begin{tabular}{|c|c|c|c|c|c|c|c|}
\hline \multicolumn{8}{|l|}{ Data: for US and EU15 } \\
\hline \multirow[t]{2}{*}{ Quantities } & \multirow[t]{2}{*}{ Data } & \multicolumn{2}{|c|}{ Shopping Model } & \multicolumn{4}{|c|}{ IRBC } \\
\hline & & Bench & Armington & Match Y & Match C & As Z & MRS/MN \\
\hline \multicolumn{8}{|l|}{ A. Variance (US) } \\
\hline Output & 1.76 & 1.75 & 1.76 & 1.75 & 0.60 & 0.57 & 0.57 \\
\hline Consumption & 0.98 & 1.52 & 1.14 & 36.83 & 0.98 & 0.08 & 0.26 \\
\hline Investment & 13.74 & 21.88 & 16.76 & 335.11 & 20.35 & 12.82 & 14.30 \\
\hline Employment & 1.16 & 1.44 & 1.40 & 2.62 & 0.11 & 0.05 & 0.06 \\
\hline Net exports & 0.16 & 0.44 & 0.16 & 0.19 & 0.01 & 0.01 & 0.01 \\
\hline TFP & 0.63 & 0.29 & 0.30 & 0.38 & 0.38 & 0.28 & 0.28 \\
\hline Terms of trade & 4.98 & 6.39 & 5.37 & 1.43 & 0.10 & 0.06 & 0.07 \\
\hline \multicolumn{8}{|c|}{ B. International comovement } \\
\hline Output & 0.40 & 0.40 & 0.41 & 0.40 & 0.26 & 0.26 & 0.26 \\
\hline Consumption & 0.25 & 0.15 & 0.28 & 0.47 & 0.25 & 0.23 & 0.15 \\
\hline Investment & 0.23 & -0.65 & -0.35 & 0.62 & 0.27 & 0.14 & 0.16 \\
\hline Employment & 0.21 & 0.15 & 0.23 & 0.48 & 0.26 & 0.30 & 0.26 \\
\hline TFP & 0.30 & 0.73 & 0.65 & 0.25 & 0.25 & 0.25 & 0.25 \\
\hline \multicolumn{8}{|c|}{ C. Co-movement within a country } \\
\hline Net exports, Output & -0.49 & -0.51 & -0.52 & -0.46 & -0.46 & -0.54 & -0.51 \\
\hline Terms of trade, Output & -0.33 & -0.51 & -0.51 & -0.34 & 0.26 & 0.49 & 0.42 \\
\hline $\mathrm{RER}, \mathrm{cH} / \mathrm{cF}$ & -0.71 & -0.96 & -0.95 & -0.95 & -0.57 & 0.27 & -0.20 \\
\hline
\end{tabular}




\section{Summary}

With demand shocks only, our shopping model can account for puzzles in the international economics:

- Backus-Smith puzzle: $\operatorname{corr}(R E R, \mathrm{cH} / \mathrm{cF})<0$

- Countercyclical terms of trade

- Volatile net exports

- International consumption correlation smaller than output correlation 


\section{References}

Backus, D.K. and G.W. Smith. 1993. "Consumption and real exchange rates in dynamic economies with non-traded goods." Journal of International Economics 35 (3):297-316.

Bai, Yan, José-Víctor Ríos-Rull, and Kjetil Storesletten. 2011. “Demand Shocks as Productivity Shocks." Working Paper, Federal Reserve Bank of Minneapolis.

Corsetti, G., L. Dedola, and S. Leduc. 2008. "International risk sharing and the transmission of productivity shocks." Review of Economic Studies 75 (2):443-473.

Engel, C. and J. Wang. 2011. "International trade in durable goods: Understanding volatility, cyclicality, and elasticities." Journal of International Economics 83 (1):37-52.

Karabarbounis, L. 2012. "Home Production, Labor Wedges, and International Real Business Cycles." Tech. rep., National Bureau of Economic Research. 


\section{Portfolio Problems in an Economy without profits}

- The numeraire is country $A$ good

$$
\begin{gathered}
V^{j}\left(z^{A}, z^{B}, K^{A}, K^{B}, A, a\right)=\max _{b^{a}, b^{B}} u(c)+ \\
\beta E\left\{V^{j}\left(z^{A^{\prime}}, z^{B^{\prime}}, K^{A^{\prime}}, K^{B^{\prime}}, A^{\prime}\left(z^{\prime}\right), a\left(z^{\prime}\right)\right)\right\} \\
\text { s.t. : } \quad c+K^{A^{\prime}} b^{A A}+p K^{B^{\prime}} b^{A B}=a+w^{j} \\
a^{\prime}\left(z^{\prime}\right)=b^{A} K^{A^{\prime}}\left[F_{K}^{A}\left(z^{A^{\prime}}, K^{A^{\prime}}\right)+1-\delta\right]+ \\
b^{A B} K^{B^{\prime}}\left[F_{K}^{B}\left(z^{B^{\prime}}, K^{B^{\prime}}\right)+1-\delta\right] p\left(S^{\prime}\right)
\end{gathered}
$$

Think for now that $P^{A}\left(S^{\prime}\right)=P^{B}\left(S^{\prime}\right)=1$. To have changes in relative prices is a bit harder but not too much. Market clearing is

$$
B^{A, A}+B^{B, A}=1 \text { and } \quad B^{A, B}+B^{B, B}=1 .
$$




\section{Portfolio Problems in an Economy with profits}

- Numeraire is the Country $A$ consumption

$$
\begin{aligned}
& V^{A}\left(z^{A}, z^{B}, K^{A}, K^{B}, A, a\right)=\max _{b^{a}, b^{B}} u(c)+ \\
& \beta E\left\{V^{A}\left(z^{A^{\prime}}, z^{B^{\prime}}, K^{A^{\prime}}, K^{B^{\prime}}, A^{\prime}\left(z^{\prime}\right), a\left(z^{\prime}\right)\right)\right\} \\
& \text { s.t. : } \quad c+\left[\Omega^{A}(S)-R^{A}(S)\right] b^{A A}+\left[\Omega^{B}(S)-R^{B}(S)\right] b^{A B}=a+w^{A} \text {, }
\end{aligned}
$$$$
a^{A^{\prime}}\left(z^{\prime}\right)=b^{A A} \Omega^{A^{\prime}}\left(S^{\prime}\right)+b^{A B} \Omega^{B}\left(S^{\prime}\right) \text {. }
$$

Note that both the value of firm $A$ and that of firm $B$ is denoted in consumption of good $A$.

Think for now that $P^{A}\left(S^{\prime}\right)=P^{B}\left(S^{\prime}\right)=1$. To have changes in relative prices is a bit harder but not too much.

Market clearing is

$$
B^{A, A}+B^{B, A}=1, \quad \text { and } \quad B^{A, B}+B^{B, B}=1 .
$$

